\title{
ANAESTHETIC MANAGEMENT OF A PATIENT WITH PENETRATING THORACIC AND CARDIAC INJURIES IN EMERGENCY DEPARTMENT
}

Joyanta Kumar Choudhury1, Dilip Kumar Saloi²

\section{HOW TO CITE THIS ARTICLE:}

Joyanta Kumar Choudhury, Dilip Kumar Saloi. "Anesthetic Management of a Patient with Penetrating Thoracic and Cardiac Injuries in Emergency Department". Journal of Evolution of Medical and Dental Sciences 2015; Vol. 4, Issue 65, August 13; Page: 11412-11416, DOI: 10.14260/jemds/2015/1646

\begin{abstract}
Thoracic injuries may be associated with life threatening cardiac injury necessitating immediate surgical intervention in an emergency operation theatre at odd hours with limited investigations and resources. Pre Anaesthetic optimization by maintenance of adequate tissue oxygenation with optimal blood volume replacement and judicious use of inotropes, determine outcome of such emergency procedures. Careful selection of Anaesthetic techniques and drugs particularly the inducing agents like Ketamine hydrochloride can be life-saving. We are discussing Anaesthetic management of a 24 year old victim of road traffic accident brought to the Emergency Department in a state of unconsciousness and shock due to penetrating chest injury with multiple rib fractures, pleural laceration, pericardial laceration and diaphragmatic tear. The patient was put up for emergency exploration and repair. CT scan ruled out head injury and Abdomen was soft and ultrasound detected no obvious intra-abdominal injury or collections.
\end{abstract}

KEYWORDS: Open pericardium, Pleural laceration, Diaphragmatic tear, Ketamine Hydrochloride.

INTRODUCTION: Cardiothoracic surgeries are conventionally carried out as routine procedure after multi systemic evaluations and anaesthetic optimization, however cardiothoracic injuries may report to Emergency department necessitating urgent intervention without adequate evaluation, in such situation Careful selection of Anaesthetic technique and anaesthetic drugs and agents may be lifesaving.

In spite of availability of specialized critical care ambulances with trained responders and rapid transportation facilities, mortality of patients with cardio thoracic injuries are as high as 60 80\%. Before arrival at Emergency Department.1,2 Survival of patients with cardio thoracic injuries depend on nature and extent of injuries, pre hospital support, treatment and status of the patient on admission. ${ }^{2}$ High degree of suspicion and clinical acumen is required during evaluation of penetrating thoracic injuries because; clinical signs of pulse deficit or murmur may be absent despite presence of significant vascular injuries. ${ }^{1}$

Pre hospital recognition of extent of cardiac injury is important as sometimes resuscitative measures like large volume fluid infusion and external cardiac compressions can contribute to worsened outcome.

We present the Anaesthetic management of a victim of road traffic accident sustaining high intensity penetrating cardio thoracic trauma, planned for emergency exploration and repair.

CASE HISTORY: A 24 year old male victim of road traffic accident (Hit by a fast moving excavator) reported to the Emergency Department in a state of unconsciousness and shock due to penetrating chest injuries. Patient was initially treated in a local hospital with intravenous fluids, and supplemental oxygen via face mask. 
On admission patient was unconscious and in a state of hypovolamic shock due to haemorrhage. He sustained severe open thoracic injury exposing the left lung and the heart. The pericardium and the pleura got lacerated and opened with multiple rib fractures $\left(4^{\text {th }}, 5^{\text {th }}, 6^{\text {th }} \& 7^{\text {th }}\right.$ ribs). There was facial injury but the airway was patent. Periphery was cold, he was pale and tachypneic with shallow breathing $\left(\mathrm{SpO}_{2} 87 \%\right)$, radial pulse was not palpable however brachial Pulse was $145 / \mathrm{min}$ and feeble, blood pressure was $80 / 46 \mathrm{~mm}$ of $\mathrm{Hg}$. There was crepitus all over the chest with presence of bilateral air entry but it was drastically diminished over left lower zone. Abdomen was soft and ultrasound detected no obvious intra-abdominal injury or collections. Urine output was $20 \mathrm{ml}$. Blood samples were sent for all investigations.

Investigations: Computed tomography scan ruled out any head and neck injury. Ultrasound detected no obvious intra-abdominal injury or collections, X-ray chest revealed fractures of left $4^{\text {th }}, 5^{\text {th }}, 6^{\text {th }} \& 7^{\text {th }}$ ribs. Haemoglobin was $8.2 \mathrm{gm} / \mathrm{dl}$ and all other haematological and biochemical investigations were within normal limits.

Anaesthetic Management: The patient was intubated by the attending Anaesthesiologist in the Emergency Department examination bay with an 8.0 sized cuffed endotracheal tube and ventilated manually with $100 \%$ oxygen. A nasogastric tube was inserted for aspiration of the gastric contents.

Colloid resuscitation was started immediately through one 18G IV cannula and four units of whole blood ordered.

A triple lumen central venous catheter was placed in the right subclavian vein and central venous pressure (CVP) was monitored which was $2 \mathrm{~cm}$ of $\mathrm{H}_{2} \mathrm{O}$. Catheterization was done to monitor urine output.

The patient was shifted to emergency operation theatre after obtaining informed and written consent. The patient regained fair amount of hemodynamic stability and consciousness due to active resuscitation. Blood sample was sent for $A B G$ analysis from right radial artery; results were near normal as the sample was taken after resuscitation. His pre induction vitals recorded were $\mathrm{SpO}_{2} 92 \%$, blood pressure 90/50 mm of $\mathrm{Hg}$, pulse rate 124/min and ECG displayed sinus tachycardia.

The patient was administered Inj. Glycopyrrolate $0.2 \mathrm{mg}$ and induced with Inj. Ketamine 100 mg intravenously. Ketamine was considered ideal as the patient was hypovolamic and already intubated. A non-depolarizing muscle relaxant (Inj. Vecuronium bromide) was used for maintenance of muscle relaxation all throughout the surgery. Inj. Fentanyl 100 mcg administered intravenously. He was administered Inj Pantoprazole and Inj Ondansetron in the emergency department.

Patient was later connected to a Dragger Fabius+Anaesthesia work station and ventilated with $100 \%$ oxygen. ${ }^{3}$

During surgery the patient was transfused four units of whole blood, 1 litre of colloid and 2 litres of crystalloids. Urine output was $150 \mathrm{ml}$ at the end of surgery. Neuromuscular blockade was not reversed as the patient was planned for post-operative ventilatory support in ICU.

Considering intensity of the injury and condition of the patient, procedures of resuscitation, pre-operative optimization and conduct of Anaesthesia was carried out by experienced Anaesthesiologists in the emergency department and surgery was performed by a team of General and CTVS surgeons. 
Operative Procedure: Initially $4^{\text {th }}, 5^{\text {th }}, 6^{\text {th }} \& 7^{\text {th }}$ ribs were resected to prevent further injuries to pleura and profusely bleeding intercostal vessels were ligated for proper haemostasis.

Multiple pleural lacerations were repaired after evacuation of blood clots and collections. The heart was exposed through approximately $4 \mathrm{~cm}$ long pericardial tear with profusely bleeding vessels. Proper haemostasis was attained after ligation of the pericardial vessels.

Pericardial laceration was repaired leaving a window opening to facilitate drainage of pericardial collection into the pleural cavity. Pleural cavity was connected to the water seal drainage bag through Intercostal drainage tube. Diaphragmatic tear was repaired.

DISCUSSION: The patient sustained injuries due to high intensity impact of the hoe of a fast moving excavator which caused severe open thoracic injury exposing the heart and the left lung. The pericardium and the pleura got lacerated and opened with multiple rib fractures. Cardiac injuries of such high intensity impact are classically associated with massive Haemorrhage, Pericardial tamponade and Cardiac failure.4-6 Haemorrhage can be massive and fatal if the great vessels are involved or damage to the heart is extensive, however this patient attained a state of near exsanguinations due to injuries of the chest wall, lacerated intercostal vessels, penetrating injuries to the left lung and pleural with considerable bleeding from the pericardial tear.

Majority of penetrating cardiac injuries usually present with Cardiac tamponade. ${ }^{5}$ Pericardial tamponade classically results in the acute cardiac compression triad of Beck, comprising of decreased arterial pressure, increased central venous pressure, and distant heart sounds. Although clearly pathognomonic for tamponade, Beck's triad occurs in only $10 \%$ of individuals with pericardial tamponade. ${ }^{7}$

Manifestation of cardiac tamponade was not evident in this case as there was pericardial tear with laceration that facilitated drainage of collected blood to the pleural cavity. Pericardial laceration was repaired leaving a window open to facilitate drainage of pericardial sac into the pleural cavity. Pleural cavity was connected to the water seal drainage bag through an Intercostal drainage tube.

Cardiac failure is commonly associated with massive valvular injuries; injuries to the coronary vasculatures or the conduction system, such injuries were not present in our patient.

The patient reported to the Emergency department with blood pressure of $80 / 46 \mathrm{mmHg}$ which came up to $90 / 50 \mathrm{mmHg}$ after adequate volume replacement with colloids and crystalloids. Dopamine infusion ( $7 \mathrm{mcg}$ per kg per minute) was started for maintenance of adequate blood pressure and organ perfusion. Blood and blood components were warmed and transfused rapidly after control of haemorrhage. ${ }^{8}$

Selection of induction agents was crucial as induction of Anaesthesia is associated with considerable fall of blood pressure; we have chosen Ketamine and Fentanyl as many researchers advocated Ketamine alone or Ketamine with opiate (Fentanyl, Alfentanyl) in such situations. ${ }^{7}$

Ketamine is widely advocated as an ideal inducing agent in a state of hypovolamic shock. $9,10,11$

Ketamine is considered the induction agent of choice with the most favourable pharmacological properties conferring haemodynamic stability. ${ }^{12}$

No volatile anaesthetics could be used as only Halothane and Isoflurane were available and both were not suitable for the state of hemorrhagic shock.

Adequate volume replacement was done with blood and crystalloids after control of haemorrhage. The patient attained considerable hemodynamic stability by the end of surgery and he 
was shifted to ICU. His ICU stay was event free, he was transferred to ward on $4^{\text {th }}$ postoperative day and subsequently discharged from the hospital.

CONCLUSION: Thoracic injuries require a high degree of suspicion and clinical acumen to detect extent of associated cardiac injuries as sings \& symptoms may be often misleading. Time for thorough investigation is the limitation if condition of the patient requires urgent surgical intervention in an emergency set up. Careful selection of anaesthetic techniques, anaesthetic drugs, availability of adequate blood and blood products and judicious use of inotropes can determine success of such emergency surgeries and its clinical outcome.

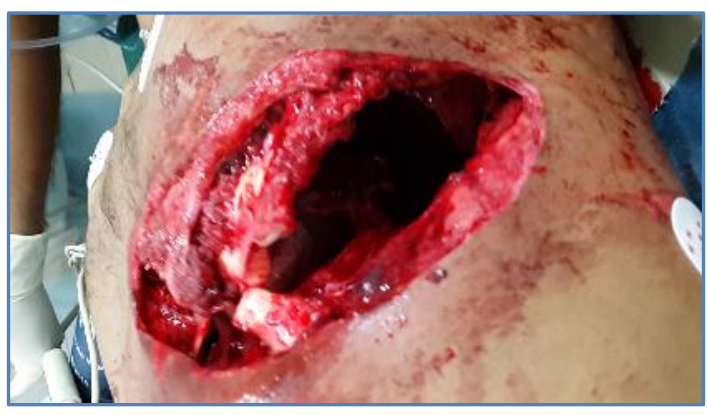

Figure 1: Open thoracic injury sustained by the patient exposing the heart and the left lung

\section{REFERENCES:}

1. Symbas PN. Cardiothoracic trauma, Philadelphia, W.B. Saunders 1989: 23.

2. Trinkle JK. Penetrating heart wounds: difficulty in evaluating clinical series. Ann Thorac Surg 1984; 38: 181.

3. Anaesthesia for Trauma, Johan K.Stene, Cristopher M. Gande, Anaesthesia 4th Ed. Chirchill Livingston 1994: 2157-2173.

4. Harman PK, Trinkle JK. Injury to the heart. In: Moore EE, Mattox KL, Feliciano DV, editors. Trauma. 2nd ed. Norwalk: Appleton and Lange; 1991.

5. Crawford FA. Penetrating cardiac injuries. In: Sabiston DC, editor. Textbook of Surgery: The Biological Basis of Modern Surgical Practice. 14th ed. Philadelphia: Saunders; 1991.

6. Sugg WL, Rea WJ, Ecker RR, Webb WR, Rose EF, Shaw RR. Penetrating wounds of the heart: An analysis of 459 cases. J Thorac Cardiovasc Surg. 1968; 56: 531-45.

7. Beck CS. Two Cardiac Compression Triads. Journal of the American Medical Association 1935; 104 (9): 714-716.

8. Karim Brohil: Thoracic trauma, Truama.org 6:6, June 2001: 1-3.

9. Emergency Anaesthetic Management of Cardio-Thoracic \& Abdominal Injury Dr. Vishal Panchamia ${ }^{1}$ Dr. Neelam Thaker ${ }^{2}$ Dr. Chetana Jadeja ${ }^{3}$ Dr. B. J. Shah ${ }^{4}$ Indian J. Anaesth. 2007; 51 (2): $131-133$.

10. Penetrating abdomino-thoracic injury with an iron rod: An anaesthetic challenge Kiranpreet Kaur, Suresh K Singhal, Mamta Bhardwaj, Prashant Kumar Indian J Anaesth. 2014 Volume: 58 Issue: 6 Page: 742-745. 


\section{CASE REPORT}

11. Emergency anaesthetic management of penetrating thoracic trauma: Combining skill with fortuity Sumanlata Gupta, Satyen Parida, Ajith Kumar Pillai, and Ramesh Varadharajan Indian J Anaesth. 2015 Mar; 59(3): 186-187.

12. Anaesthesia. 2009 May; 64(5): 532-9. doi: 10.1111/j.1365-2044.2008.05835.x. Anaesthesia in haemodynamically compromised emergency patients: does Ketamine represent the best choice of induction agent? Morris C1, Perris A, Klein J, Mahoney P.

\section{AUTHORS:}

1. Joyanta Kumar Choudhury

2. Dilip Kumar Saloi

\section{PARTICULARS OF CONTRIBUTORS:}

1. Assistant Professor, Department of Anaesthesiology \& Critical Care, Gauhati Medical College \& Hospital, Guwahati, Assam.

2. Assistant Professor, Department of Anaesthesiology \& Critical Care, Gauhati Medical College \& Hospital, Guwahati, Assam.

\section{NAME ADDRESS EMAIL ID OF THE CORRESPONDING AUTHOR:}

Dr. Joyanta Kumar Choudhury, 2C Ornate Enclave, August Kranti Path, Opposite Novadaya Jatiya Vidyalaya. Beltola Bazar Road, P. O. Beltola, Guwahati-781028, Assam.

E-mail: drjkc2008@gmail.com

Date of Submission: 24/07/2015. Date of Peer Review: 25/07/2015. Date of Acceptance: 06/08/2015. 